\title{
Ultrafine particles in inhabited areas in the Arctic - From very low to high concentrations
}

Pétursdóttir, Una; Kirkelund, Gunvor Marie; Press-Kristensen, Kåre; Hertel, Ole; Mikkelsen, Teis Nørgaard

Published in:

Atmospheric Pollution Research

Link to article, DOI:

10.1016/j.apr.2017.10.008

Publication date:

2018

Document Version

Peer reviewed version

Link back to DTU Orbit

Citation (APA):

Pétursdóttir, U., Kirkelund, G. M., Press-Kristensen, K., Hertel, O., \& Mikkelsen, T. N. (2018). Ultrafine particles in inhabited areas in the Arctic - From very low to high concentrations. Atmospheric Pollution Research, 9(2), 299-308. https://doi.org/10.1016/j.apr.2017.10.008

\section{General rights}

Copyright and moral rights for the publications made accessible in the public portal are retained by the authors and/or other copyright owners and it is a condition of accessing publications that users recognise and abide by the legal requirements associated with these rights.

- Users may download and print one copy of any publication from the public portal for the purpose of private study or research.

- You may not further distribute the material or use it for any profit-making activity or commercial gain

- You may freely distribute the URL identifying the publication in the public portal 


\section{Highlight}

- A 10-day heatwave was superimposed to elevated temperature and $\mathrm{CO}_{2}$ around flowering

- The applied heatwave decreased barley yield by $52 \%$

- Aboveground vegetative biomass increased from heatwave exposure

- 22 barley accessions showed variation in decreased yield and stability of yield 
1 How a 10-day heatwave impacts barley grain yield when superimposed onto future

2 levels of temperature and $\mathrm{CO}_{2}$ as single and combined factors

4 Cathrine H. Ingvordsen

5 cathrine.ingvordsen@ csiro.au

6 Technical University of Denmark, Ris $\varnothing$ Campus, Frederiksborgvej 399, DK-4000

7 Roskilde, Denmark

8 Present address: Black Mountain Laboratories, GPO Box 1600, Canberra, ACT, 2601,

$9 \quad$ Australia

10 Corresponding author: T +61 0402475 053, M cathrine.ingvordsen@csiro.au

12 Michael F. Lyngkjær

13 mlyn@plen.ku.dk

14 University of Copenhagen, Section for Plant Biochemistry, Thorvaldsensvej 40, DK-

151871 Frederiksberg C, Denmark

\section{Pirjo Peltonen-Sainio}

18 pirjo.peltonen-sainio@luke.fi

19 Natural Resources Institute Finland (Luke), Management and Production of Renewable

20 Resources, Latokartanonkaari 9, FI-00790 Helsinki, Finland

\section{Teis N. Mikkelsen}

23 temi@env.dtu.dk

24 Technical University of Denmark, Dept. Environmental Engineering, AIR,

25 Bygningstorvet 115, DK-2800, Kgs. Lyngby, Denmark. 
27 Anders Stockmarr

28 anst@dtu.dk

29 Technical University of Denmark, Dept. Applied Mathematics and Computer Science,

30 Matematiktorvet, Bld. 324, 2800 Kgs. Lyngby, Denmark

31

32 Rikke B. Jørgensen

33 rijq@env.dtu.dk

34 Technical University of Denmark, Dept. Environmental Engineering, AIR,

35 Bygningstorvet 115, DK-2800, Kgs. Lyngby, Denmark 


\section{Abstract}

37 Heatwaves pose a threat to crop production and are predicted to increase in frequency,

38 length and intensity as a consequence of global warming. Future heatwaves will occur

39 in addition to the ongoing increase of mean temperature and $\mathrm{CO}_{2}$. To test effects of

40 heatwaves superimposed to future climate scenarios, 22 barley accessions were

41 cultivated with elevated temperature $\left(+5^{\circ} \mathrm{C}\right)$ and $\mathrm{CO}_{2}(700 \mathrm{ppm})$ as single factors and in

42 combination. The control treatment mimicked ambient Scandinavian early summer

43 conditions $\left(19 / 12^{\circ} \mathrm{C}\right.$, day/night; $\left.400 \mathrm{ppm} \mathrm{CO}_{2}\right)$. Around flowering a 10-day heatwave of

$4433 / 28^{\circ} \mathrm{C}$ (day/night) was superimposed to all treatments. The lowest average grain yield

45 was observed when the heatwave was superimposed onto the combined elevated

46 temperature and $\mathrm{CO}_{2}$ treatment. Here the yield decreased by $42 \%$ compared to no

47 heatwave and 52\% compared to ambient conditions. When the heatwave was

48 superimposed onto ambient conditions the average grain yield decreased by $37 \%$

49 compared to no heatwave. There was no significant difference between the relative

50 grain yield decrease caused by the heatwave in the ambient and future climate scenarios.

51 In contrast, the vegetative aboveground biomass increased upon heatwave exposure,

52 leading to a strong decline in the harvest index. Our results strongly emphasize the need

53 to produce heatwave resilient cultivars.

55 Keywords: Biomass, extreme events, genotype differences, heat exposure, Hordeum

56 vulgare L., multifactor treatment, stability 
60 Extreme weather events like heatwaves, floods, droughts and storms cause acute

61 changes in growth conditions determining primary production (Fischer and Schär, 2009;

62 Hajat et al., 2010; Collins et al., 2013). Collected data from recent decades together

63 with results from simulation studies suggest that the variability within seasons can be

64 more unfavorable for crop production than the general changes from season to season

65 (Reyer et al., 2013; Gourdji et al., 2013, Tack et al., 2015). In a statistical study, inter-

66 annual climate variability was shown to account for $>60 \%$ of maize, rice, wheat and

67 soybean yield variability (Ray et al., 2015). Hence, large variations in the climate within

68 the crop seasons, such as a heatwave, are detrimental for the end result.

69 In the 2012-2013 growth season Australia experienced what became known as the

70 'angry summer', where over 100 temperature records were broken (BoM, 2014). An

71 extreme heatwave caused large scale yield failures in Russia in 2010 (Trenberth and

72 Fasullo, 2012), and Europe experienced extreme heatwaves in 2003 and 2006. In 2003,

73 the European heatwave caused a $21 \%$ decrease in the French wheat production as

74 temperatures were up to $6^{\circ} \mathrm{C}$ above long-term means and precipitation being less than

$7550 \%$ of the average (Ciais et al., 2005). Losses in cereal crop production from heat and

76 drought in the period from 1964 to 2007 were showed to reach 9-10\% globally with the

77 highest losses in recent years (Lesk et al., 2016). Unfortunately, predictions are that

78 global warming will make summer heatwaves more frequent and severe together with

79 decrease in precipitation during the summer period (Meehl and Tebaldi, 2004; Fischer

80 and Schär, 2010; Collins et al., 2013).

81 In the north of Europe, barley (Hordeum vulgare L.) - especially spring barley - is the

82 cereal species occupying most of the cultivated area (19\%), and the grains are 
predominantly used for feed and malt (FAOSTAT 2017). The annual average increase

84 in grain yield of barley and wheat (Triticum aestivum L.) observed up to 1995 has ceased in Scandinavia (FAOSTAT, 2017). Stagnation of grain yield might, at least partly, is alleviated by the development of climate resilient cultivars. However, to

87 develop climate resilient cultivars, assessing the effects of the most likely and relevant 88 climate changes to a range of genotypes is essential. Studying the effects of future 89 extreme events are challenging due to the high complexity of their timing, frequency and intensity, and the fact that they will be superimposed on the seasonal changes.

91 The effect of elevated temperature (eTmp) and elevated atmospheric carbon dioxide concentration $\left(\mathrm{eCO}_{2}\right)$ on grain yield have been evaluated as single-factors and combined-factors under experimental conditions in FACE (free air carbon dioxide enrichment) and in enclosure studies as well as in simulation studies (Lawlor and Mitchell, 1991; Conroy et al., 1994; Jablonski et al., 2002; Ainsworth and Long, 2005; Lobell et al., 2011; Challinor et al., 2014; Ingvordsen et al., 2015a; Cai et al., 2016). grain yield from $\mathrm{eCO}_{2}$. In combinations, the harmful effect of eTmp is not fully complemented by $\mathrm{eCO}_{2}$, and therefore, grain yield generally decreased (Conroy et al., 1994; Long et al., 2006; Ingvordsen et al., 2015a). The above mentioned studies all reported results from a maximum of four accessions, and crop responses to climate change are almost exclusively reported from studies including a very limited number of genotypes. In contrast the present study includes 22 accessions representing a diverse genetic origin and thereby widening our knowledge on genotypic effects in response to 105 eTemp and $\mathrm{eCO}_{2}$. yield differently than exposure to an extreme temperature event like a heatwave. The 
108 negative effect of a heatwave on grain yield is mainly determined by the timing in 109 relation to the cereal development stage, with the most susceptible stage being around 110 flowering (Barnabas et al., 2008, Barber et al., 2017). In turn, the physiological 111 response mechanisms of individual cultivars vary and are associated with their final 112 yield (Stone and Nicolas 1994; Hakala et al., 2012). Under field conditions, the 113 differences observed in development between the accessions together with time of 114 sowing for each accession would have influenced at which development stage the 115 heatwave would have had its effect. Sufficient variability in cultivar earliness/lateness, 116 cultivation of mixed cultivars and agricultural management can enable partial escape 117 from the deleterious effects of heatwaves (Tewolde et al., 2006).

118 Few studies have so far investigated the effect on crop production caused by heatwaves 119 superimposed to projected future levels of temperature and/or $\mathrm{CO}_{2}$. One study applied a 120 15-day heatwave of maximum $35^{\circ} \mathrm{C}, 8$ hours a day during grain filling on three wheat 121 cultivars under simultaneous exposure to $\mathrm{eCO}_{2}$ (750ppm; Bencze et al., 2004).

122 However, none have, to our knowledge, applied a heatwave under the realistic future 123 climate scenario of eTmp and $\mathrm{eCO}_{2}$ in combination and assessed a large number of 124 genotypes.

125 In the present study a 10 -day heatwave of $33 / 28^{\circ} \mathrm{C}$ (day/night) was induced around the 126 time of flowering to 22 spring barley accessions. The heatwave was timed around 127 flowering, which is known to be the most critical developmental phase of barley yield 128 determination at high latitudes (Peltonen-Sainio et al., 2011). The heatwave was 129 superimposed to projected future levels of temperature and $\mathrm{CO}_{2}$ as single factors and 130 combined, conditions close to IPCC's worst case scenario for the end of this century 131 ( RCP8.5; Collins et al., 2013). We ask if heat waves will be more or less devastating 
132 when superimposed on future growth conditions with eTmp and $\mathrm{eCO}_{2}$ considering grain 133 yield, biomass, calculated harvest index (HI) and stability of grain yield.

\subsection{Plant material}

139 Based on their performance, 22 barley (Hordeum vulgare L.) accessions were selected

140 from a previous study on production under eTmp, $\mathrm{eCO}_{2}$, and $\mathrm{eCO}_{2}$ combined with

141 eTmp (Ingvordsen et al., 2015a). The accessions represent both high and low yielding 142 lines and include landraces, old (1924-1962) and new (1978-2010) cultivars. Details on 143 the 22 accessions can be found in Table 1. The accessions were supplied by NordGen 144 (the Nordic Genetic Resource Center; http://www.nordgen.org/) and Nordic breeding 145 companies.

148 The accessions were cultivated in the RERAF (Risø Experimental Risk Assessment

149 Facility) phytotron at the Technical University of Denmark, Campus Ris $\varnothing$, Roskilde.

150 RERAF has the advantage of six identical $24 \mathrm{~m}^{2}(6 \mathrm{~m} \times 4 \mathrm{~m} \times 3 \mathrm{~m})$ gastight chambers

151 individually programmed and with continuous measurements of the experimental

152 conditions. The light regime mimicked the long days of southern Scandinavia (May-

153 July) with 16 hours of light and 8 hours of dark. Lamps were controlled to imitate 
154 sunrise and sunset (one hour each) in the beginning and end of the light regime. Light 155 intensity was in PAR (photosynthetically active radiation) averaged at approximately 400 mol photons $\mathrm{m}^{-2} \mathrm{~s}^{-1}$ at canopy height. Each accession was grown in $11 \mathrm{~L}$ pots filled

157 with $4 \mathrm{~kg}$ of sphagnum substrate (Pindstrup Substrate No. 6, Pindstrup Mosebrug A/S,

158 Denmark) supplemented with $10 \mathrm{~g}$ NPK fertilizer (21-3-10, Yara) at sowing. Per

159 accessions twelve seeds were sown in each of two pots, and at the seedling stage thinned to eight experimental plants per pot. The pots were placed on wheeled growing tables; one pot remained in the basic treatment the other was moved to the heatwave treatment at Zadoks growth stage 49 (first awns visible; ZS, Zadoks et al., 1974; Fig. 1). Throughout the experiment $4.4 \mathrm{~L} \mathrm{~m}^{-2}$ day $^{-1}$ of water was applied in all treatments at the beginning of the daytime regime by an automated surface dripping system. At the early stages of growth (seedling stage), excess water was drained from the pots. Watering was reduced stepwise, when plants in a given treatment started ripening, ZS 90, and watering was ended at maturity, ZS 99. The growth stage was determined in the control treatments. The amount of water supplied was sufficient to avoid water limitation during growth under ambient conditions. Relative humidity was constant at 55/70 \% (day/night) for all treatments. At growth day 27, about ZS 15-17, all plants were treated

171 prophylactically against aphids with Confidor WG 70 (Bayer A/S). To avoid any unintended chamber specific effects the treatments were rotated between chambers once

173 a week. When chamber rotations took place, conditions in all chambers were set to

174 ambient, and the batches of plants were moved to their new chamber, and the corresponding treatment applied again. The chamber rotation was accomplished within one hour (all inclusive). Concurrent with the chamber rotation all tables were rotated

177 within the treatments according to a scheme, so that any table/pot received a new 178 position in the chamber (e.g. pots facing the outer rim were moved to the center etc.). 
179 Further, the positions of the accessions were identical between treatments. The rotation 180 between chambers was ended 68 days after sowing to avoid plant damage, when 181 moving the wheeled tables through the chamber doors.

\subsection{Treatments}

184 The barley accessions were cultivated under four climatic scenarios referred to as basic 185 treatments. The basic treatments were: 1) ambient (amb), mimicking south

186 Scandinavian summer conditions with $19 / 12^{\circ} \mathrm{C}$ (day/night) and $\mathrm{CO}_{2}$ concentration at 400ppm; 2) constantly elevated temperature (eTmp) with $+5^{\circ} \mathrm{C}$ day/night; 3) constantly 188 elevated $\mathrm{CO}_{2}\left(\mathrm{eCO}_{2}\right)$ with $\left.+300 \mathrm{ppm} ; 4\right)$ combined constantly elevated temperature and $189 \mathrm{CO}_{2}(\mathrm{eTmp \& eCO} 2)$. The eTmp and $\mathrm{eCO}_{2}$ were set close to those projected by IPPC for 190 the Nordic region at the end of the $21^{\text {st }}$ century (Collins et al., 2013).

191 The heatwave treatments were superimposed to the basic treatments (then designated $192 \mathrm{amb}+\mathrm{H}, \mathrm{eTem}+\mathrm{H}, \mathrm{eCO}_{2}+\mathrm{H}, \mathrm{eTmp} \& \mathrm{eCO}_{2}+\mathrm{H}$ ) as constant hot temperature $33 / 28^{\circ} \mathrm{C}$ 193 (day/night) for 10 days and applied individually to the accessions around anthesis. 194 When half of the plants of a given accession had reached ZS 49 (first awns visible), one 195 of the pots was moved to the heatwave treatment. The $\mathrm{CO}_{2}$ concentration in the 196 heatwave treatment followed the climatic scenarios and was $400 \mathrm{ppm}$ for amb+H and $197 \mathrm{eTem}+\mathrm{H}$ and 700ppm for $\mathrm{eCO}_{2}+\mathrm{H}$, eTmp\&eCO $\mathrm{CO}_{2}+\mathrm{H}$. Throughout the heatwave 198 treatment, watering was applied in a volume of $4.4 \mathrm{~L} \mathrm{~m}^{-2}$ day $^{-1}$ as in the basic 199 treatments. After the heatwave treatment the pot was transferred back to its original 200 basic treatment. The experimental setup is shown in Fig. 1. 
203 Plants were harvested individually and dried for a minimum of three weeks $\left(20^{\circ} \mathrm{C}\right.$, continuous high air flow, 55\% relative humidity). After threshing, grain yield (g plant ${ }^{-1}$ ) and aboveground vegetative biomass (g plant ${ }^{-1}$ ) were sized. Harvest index (HI; grain yield proportional to total aboveground biomass, \%) was calculated from grain yield and aboveground biomass. Stability measures over the eight treatments were calculated by the static environmental variance $\left(S^{2}\right.$; Roemer, 1917) and the dynamic Wricke's ecovalence $\left(\mathrm{W}^{2}\right.$; Wricke, 1962) according to

$$
S_{i}^{2}=\sum\left(R_{i j}-m_{i}\right)^{2} /(e-1)
$$

$$
W^{2}{ }_{i}=\sum\left(R_{i j}-m_{i}-m_{j}+m\right)^{2}
$$

212 where $R_{i j}$ is the observed yield of the accession $i$ in the treatment $j, m_{i}$ is mean yield of

213 the accession across treatments, $e$ is number of environments, $m$ is the average of all $m_{i}$

214 termed the grand mean. To the raw data a mixed effects model with randomized

215 accession and pot effects was applied to verify treatment effects, of eTmp, $\mathrm{eCO}_{2}, \mathrm{H}$, and 216 their interactions. Random interactions between accession and treatments eTmp, $\mathrm{eCO}_{2}$

217 and $\mathrm{H}$ were investigated and rendered insignificant prior to analysis of treatment effects.

218 To investigate potential impact of the individual accessions, a derived mixed effects

219 model with fixed effects of accessions instead of random was constructed, including

220 fixed effects of accessions and interaction effects between accessions and the eTmp,

$221 \mathrm{eCO}_{2}$ and $\mathrm{H}$ treatments. The pot effect was initially investigated through Maximum

222 Likelihood estimation, which considered potential within-pot-competition effects. After

223 establishing a positive within-pot correlation, the analysis was carried out with standard

224 software for mixed effects models. This model formula and parameter estimates are

225 described in detail in the Supplementary material. Furthermore, accessions were 
226 grouped into landraces, old and modern cultivars, and the mixed effects model with

227 random pot effect and accessions replaced with the grouping was analyzed. A similar

228 model was applied to above ground vegetative biomass, and analyzed. Presented

229 parameters (see supplementary material) were constructed with the REML procedure.

230 Estimates, confidence intervals and p-values in for ratios Table 2 and ratio comparisons

231 for relative heatwave effects were constructed through simulation. Significance levels

232 are $p<0.001:^{* * *} ; p<0.01:^{* *} ; p<0.05:^{*}$. All modelling and correlation analysis was

233 carried out using the software package R, version 3.2.3 (R Core Team, 2015).

236 3. Results

2383.1 Experimental levels of temperature, $\mathrm{CO}_{2}$ and humidity

239 The levels of temperature, $\mathrm{CO}_{2}$ and humidity applied in RERAF throughout plant

240 cultivation were according to set points (Supplementary Table S1), except for the

241 ambient $\mathrm{CO}_{2}$ treatment. Here the averaged value reached $452.71 \mathrm{ppm}( \pm 33.53)$ around

$24250 \mathrm{ppm}$ higher than set value. The RERAF facility lacks the mechanism to absorb $\mathrm{CO}_{2}$,

243 hence plant and especially soil respiration have potentially caused the higher values.

244 The hypothesis on respiration being the responsible factor was supported by the

245 overshoots of the set-point value being most prominent within the first hours of the day

246 and during the night regime (data not shown). 
249 Comparing the elevated $\mathrm{CO}_{2}$ and temperature treatments with ambient conditions

250 (Table 2), the effect of $\mathrm{eCO}_{2}$ was found to increase overall grain yield by about $26 \%$,

251 while eTmp decreased overall grain yield by $43 \%$. When the single factors were

252 combined in eTmp\&eCO $\mathrm{C}_{2}$ treatment, grain yield decreased by about $18 \%$. Interestingly,

253 the effect of the combined factors seemed to be additive with a non-significant

254 interaction $(p=0.25)$. Total aboveground vegetative biomass was also increased $(35 \%)$

255 by $\mathrm{eCO}_{2}$, whereas eTmp caused a moderate decrease of almost $5 \%$. In the two-factor

256 eTmp\&eCO ${ }_{2}$ treatment the aboveground vegetative biomass increased $20 \%$. The effects

257 of $\mathrm{eCO}_{2}$ and eTmp were not additive for aboveground vegetative biomass ( $\left.p=0.03\right)$;

258 thus, the effect of the two individual factors combined could not be predicted from the

259 effect of the individual factors. The treatment effects on grain yield and aboveground

260 vegetative biomass were reflected in the Harvest Index (HI), which was significantly

261 reduced in the two treatments with eTmp, while $\mathrm{eCO}_{2}$ had no effect on HI. Hence,

262 increase in grain yield and aboveground vegetative biomass was proportionally similar

263 to the that in the amb treatment. The modelled production parameter estimates for the

264 accessions are presented in Table 2. The basic treatments resemble the set up in our

265 previous study that also included the same accessions (Ingvordsen et al., 2015a), and

266 Pearsons correlation coefficient on grain yield between the previous and present

267 experiments was high $(74-82 \%, p<0.001)$.

268 The accessions reached the transfer-stage (ZS 49) earliest in the two-factor

269 eTmp\&eCO $\mathrm{C}_{2}$ treatment, on average 45.5 days after sowing, 5 days earlier than in the

270 ambient treatment (Supplementary Fig. S1). 
273 All 22 accessions survived the 10-day heatwave applied around anthesis (due to faulty

274 watering in the eTmp $+\mathrm{H}$ treatment of cultivar Drost P., data for this accession and

275 treatment were excluded from the measured results). From the modelled estimates in

276 Table 2, average grain yield was found to decrease 52\%, when comparing the future

277 eTmp\&eCO $\mathrm{CO}_{2}+\mathrm{H}$ scenario with the basic amb scenario, indicating severe production loss

278 under future conditions $(p<0.0001)$. The relative production loss caused by the

279 heatwave is not significantly different in the future and ambient scenario $(p=0.71)$. The

280 relative effect of the heatwave was independent of the basic treatment in all scenarios,

281 with $p>0.13$. On the basis of the similar relative decrease caused by the superimposed

282 heatwave, we estimated the relative effect on overall grain yield as a $39 \%$ decrease.

283 Given the similar relative effect of the superimposed heatwave, the highest grain yield

284 was found in the treatment of $\mathrm{eCO}_{2}+\mathrm{H}$ at $5.23 \mathrm{~g} \mathrm{plant}^{-1}$, pooling all accessions (Table 2).

285 The production of aboveground vegetative biomass was in all basic treatments increased

286 by heatwave exposure, however not significantly for eTmp (Table 2). As the heatwave

287 decreased yield and increased aboveground vegetative biomass in all basic treatments,

288 HI was decreased accordingly suggesting change in allocation from grain to vegetative

289 biomass (Table 2).

\subsection{Accession specific effects}

292 The days for the individual accession to reach the transfer-state at ZS 49 was influenced

293 by the basic treatments. The first accession to reach ZS 49 and being transferred to the

294 heatwave was the old Swedish cultivar 'Mari' grown under eTmp, and the last

295 accession was the landrace 'Griechische', transferred 35 days later, also grown under 
296 eTmp (Supplementary Fig. S1). The modern Danish cultivar 'Sebastian' and the

297 landraces 'Solenbyg' and 'Grenoble I' spanned only 2-5 days in reaching ZS 49 over all

298 four of the basic treatments, demonstrating stable rate of development. Early accessions,

299 reaching the transfer-state first under all basic treatments, were two modern Norwegian

300 cultivars, 'Arve' and 'Brage', two old Swedish cultivars, 'Brio' and 'Mari' and the

301 landraces 'Bjørne' and 'Kushteki' (Supplementary Fig. S1).

302 The analysis showed that in our experimental setup heatwave effects were not

303 significantly dependent on the barley accession $(p=0.08)$. However, the negative grain

304 yield effects by the heatwave treatments varied among the 22 accessions and ranged

305 from $32 \%$ to $54 \%$ reduction in the $\mathrm{amb}+\mathrm{H}$ and from $55 \%$ to $72 \%$ reduction in the

306 eTmp\&eCO ${ }_{2}+\mathrm{H}$ treatments (Fig. 2). Some accessions like the landraces, Königsberg

307 and Vilm, and the Danish modern cultivar Alliot seemed to be substantially more

308 affected by the eTmp\&eCO $\mathrm{CO}_{2}+\mathrm{H}$ treatment than the amb+H treatment. In contrast, the

309 old Swedish cultivar Mari and the modern Danish cultivar Anakin showed stronger

310 decrease in grain yield under the amb+H treatment than under the eTmp\&eCO${ }_{2}+\mathrm{H}$

311 treatment, showing potential to resist heatwaves under future climate conditions. As

312 expected, the analysis revealed that the group of modern cultivars yielded significantly

313 higher than the group of landraces $(p<0.0001)$, but they did not produce more

314 aboveground vegetative biomass compared to the landraces.

315 The different responses in grain yield of the set of accessions over the eight applied

316 treatments revealed a static environmental variance, $S^{2}$, ranging from 1.80 to 9.35 ,

317 where lower values indicate static stability to environmental changes (Table 1).

318 According to $S^{2}$, the landrace 'Oslo' and the French cultivar 'Prestige' were identified

319 as most stable over all applied treatments. In addition, 'Prestige' holds the seventh

320 highest mean grain yield across treatments, whereas 'Oslo' ranked $20^{\text {th }}$ in mean yield. 
321 Wricke's ecovalence, $W^{2}$, for grain yield ranged from 2.37 to 23.32 over the eight

322 treatments, where a high ecovalence indicates larger fluctuation across the treatments

323 compared to the other accessions. The modern Danish cultivar 'Evergreen' had the

324 second highest mean grain yield over the eight treatments, however, a considerable

325 decrease in grain yield under eTmp most likely caused 'Evergreen' to be identified as an

326 accession responding differently from the majority, and ranking only $20^{\text {th }}$ out of the 22

327 for $W^{2}$. Low values of $W^{2}$ were presented by the landraces 'Kushteki' and 'Moscou' and

328 the cultivar 'Arve' released in Norway.

329 Calculating $S^{2}$ and $W^{2}$ separately over the four basic treatments and the four $+\mathrm{H}$

330 treatments showed that the accessions were either stable over the basic treatments or

331 over the $+\mathrm{H}$ treatments (Supplementary Fig. S2). The only exceptions were the landrace

332 'Oslo' and the Danish cultivar 'Alf', as they showed stable grain yield according to $S^{2}$

333 under both the four basic treatments and the four heatwave treatments. However, both

334 accessions were among the bottom three accessions for mean grain yield. No correlation

335 between grain yield in the treatments with and without heatwave could be found for

336 either $S^{2}(p=0.16)$ or $W^{2}(p=0.08)$. The lack of correlation between treatments with and

337 without heatwave suggests that the underlying mechanisms causing stability to a

338 heatwave and to eTmp and $\mathrm{eCO}_{2}$ are not the same.

\section{4. Discussion}


343 Our results support the generally observed trend of decreased grain yield in response to

344 eTmp and increased grain yield under $\mathrm{eCO}_{2}$ (Morison and Lawlor, 1999; Bokszczanin

345 and Fragkostefanakis, 2013) with the observed $26 \%$ increased grain yield by $\mathrm{eCO}_{2}$ and

346 the $43 \%$ decreased grain yield by eTmp for the 22 barley accessions in this study.

347 However, the magnitude of the observed trend varies between studies. From a FACE

348 experiment Manderscheid et al. (2009) observed $\mathrm{eCO}_{2}$ at 550ppm to increase grain 349 yield by $9-18 \%$ for the barley accession 'Theresa'. A $2^{\circ} \mathrm{C}$ temperature increase in the 350 soil (4 cm depth) under field conditions caused a $4 \%$ yield decrease in the barley 351 accession 'Quench' (Högy et al., 2013). In a phytotron study on four barley accessions 352 ('Gl. Dansk', 'Lazuli', 'Anakin' and 'Barke') overall grain yield was increased by 57\% 353 when exposed to $\mathrm{eCO}_{2}$ at $700 \mathrm{ppm}$, whilst grain yield was decreased by $27 \%$ under $+5^{\circ} \mathrm{C}$ 354 eTmp (Clausen et al., 2011). The differences may result from variation in several 355 factors such as crop species, level, timing and length of exposure to eTmp and eCO

\subsection{Response to the combined-factor basic treatment}

358 Only few experimental studies have addressed effects of combined eTmp and $\mathrm{eCO}_{2}$ 359 treatments on grain yield and biomass. In rice, the combination of eTmp and $\mathrm{eCO}_{2}$ at 360 levels predicted for the end of the 20 th century $\left(+4^{\circ} \mathrm{C}\right.$ and +200 to $\left.300 \mathrm{ppm} \mathrm{CO}_{2}\right)$ has 361 been reported to affect grain yield negatively (Ziska et al., 1997). A modelling study of 362 rice, wheat and soybean also reported decreased grain yield from the combined eTmp and $\mathrm{eCO}_{2}$ (Long et al., 2006). Our results on barley support these earlier findings from other crops, which bodes ominously for the production in a future climate, where $\mathrm{CO}_{2}$

365 and temperature will increase concerted. For grain yield we found that the effect of these two individual factors was additive and this additivity could predict the response 
367 in their combined treatment. This finding is in contrast to previous findings in a larger

368 dataset including 138 barley accessions (Ingvordsen et al., 2015a). However, interaction

369 between factors might still be present, but significance may not be detected due to the

370 smaller set of 22 accessions. In contrast, for vegetative biomass the effect of the

371 individual factors was not additive, when compared to the combined treatment, as also

372 found by Ingvordsen et al. (2015a). The incongruence in identified additive effect of

373 single factor treatments between the two studies can also reflect the variation in

374 genotypic responses in the two sets of accessions. In any case, it is crucial to screen

375 diverse sets of numerous cultivars to help fill the knowledge gap on genotype effect,

376 information of value for breeding and in modelling studies.

\subsection{Level, timing and frequency of the superimposed heatwave}

379 A heatwave is an extreme event where timing, intensity and length are difficult to 380 predict and therefore it is challenging to include such extreme events in the forecast for the cropping season and in choice of cultivar (Ben-Ari et al., 2016). In Southern

382 Scandinavia (Denmark) a heatwave is today defined as when average of maximum 383 temperatures registered over three consecutive days exceed $28^{\circ} \mathrm{C}$ (DMI, 2014). No 384 information could be found describing most likely timing, temperature regime and 385 length of future heatwaves in this northern region. In southern Europe, model prediction 386 of future heatwaves forecasts that by the end of this century heatwaves will occur with a 387 frequency between 1.7 and 2.3 times per growing season, last between 11 and 17 days, 388 and be up to $3^{\circ} \mathrm{C}$ warmer than previous heatwaves (Meehl \& Tabaldi, 2004). Hence the 389 applied heatwave in the present study is $+5^{\circ} \mathrm{C}$ warmer and 7 days longer than the 390 current Nordic definition, and likely represents a realistic future extreme temperature 
391 event. The timing with the heatwave striking at ZS49 (first awns visible) targeted the

392 sensitive stages of pollen development, anthesis and ovule formation (Sakata et al.,

393 2000; Hakala et al., 2012; Gourdji et al., 2013) and had increased effect on yield. A

394 study in maize, identified $13 \%$ decreased yield under a 3-day heatwave of $+6^{\circ} \mathrm{C}$ applied

395 at early reproductive stage (silking), but no decrease in yield when applied at early

396 vegetative stage (Siebers et al., 2017). Heat tolerance around flowering has been

397 identified as a key trait to improve the European primary production of wheat in the

398 future climate (Stratonovitch and Semenov, 2015).

401 The heatwave superimposed in the most realistic future climate treatment, eTmp\&eCO${ }_{2}$,

402 halved the grain yield (52\%) when compared to production in the climate of today

403 (amb). Halving the eatable harvest is a considerable impact potentially leading to

404 insufficient food supply. Interestingly, the results showed consistent relative decrease in

405 grain yield on all basic treatments, in response to heatwave exposure. With the

406 consistent relative heatwave response in all four basic treatments, the differences found

407 in final grain yield and aboveground biomass after superimposed heatwave were caused

408 by the basic treatments, i.e. the already present increases in temperature and $\mathrm{CO}_{2}$. One

409 can speculate if the superimposed heatwave was so severe that it caused physiological

410 processes to operate at an absolute minimum during its duration, and therefore affected

411 all basic treatments relatively uniformly. Counter to that speculation Fitzgerald et al.,

412 (2016) identified $\mathrm{eCO}_{2}$ to ameliorate the effect of an 8-day naturally occurring heatwave

413 in a semi-arid environment with temperature $>35^{\circ} \mathrm{C}$ (FACE experimental setup). The

$414 \mathrm{eCO}_{2}$ increased the yield by $17-40 \%$ during the heatwave in a modern and an old wheat 
415 cultivar respectively. However, due to the heatwave occurring naturally, there are no

416 data for the yield at ambient temperature. A study by Bencze et al. (2004)

417 superimposing a less extreme heatwave, supports our suggestion that the final grain

418 yield is determined by the basic treatment. Bencze et al. (2004) cultivated three wheat

419 cultivars at $375 \mathrm{ppm}$ and $750 \mathrm{ppm} \mathrm{CO}_{2}$ and superimposed a heat event consisting of a

420 temperature increase 8 hours a day for 15 days around grain filling at maximum $35^{\circ} \mathrm{C}$ in

421 contrast to ambient temperature at maximum $24^{\circ} \mathrm{C}$. The highest grain yield post

422 heatwave exposure was identified in the accessions exposed to the high $\mathrm{CO}_{2}$

423 concentration (Bencze et al., 2004) as observed in our study (Table 2).

\subsection{Response in biomass to the superimposed heatwave}

426 The aboveground vegetative biomass was increased by the heatwave at all basic

427 treatments, whereas grain yield decreased, hence, the allocation between vegetative

428 biomass and grain changed, as was observed in the HI (Table 2). Considering the

429 disruptive effect the heatwave had on flowering, with less grain formed, it is likely that

430 grains were not filled making resources available for vegetative biomass. Allocation

431 from reproductive biomass to vegetative biomass was also identified by Batts et al.

432 (1998) in one of two wheat cultivars exposed to a temperature gradient. As plants from

433 the basic eTemp treatment came from an environment with elevated temperature before

434 heatwave exposure, plants from the amb and $\mathrm{eCO}_{2}$ treatments experienced the highest

435 temperature increases of $+14^{\circ} \mathrm{C}\left(\mathrm{eTmp}\right.$ and eTmp\&eCO $\left.\mathrm{CO}_{2}+9^{\circ} \mathrm{C}\right)$ when transferred to the

436 heatwave, and also showed the largest gain in vegetative biomass suggesting

437 temperature to be the dominant factor for the shift in allocation. Numerous plant

438 processes are involved in the allocation of resources to organs, and HI is a good 
439 indicator for shifts in resource allocation. In addition, HI has been shown to have a high 440 heritability (Hay, 1995) and therefore, grain production under future climate conditions

441 could benefit from identification of genotypes with stable and high $\mathrm{HI}$ in a variable

442 climate. With an apparent future increase in aboveground vegetative biomass, its

443 functionality should be explored (Ghaly and Alkoaik, 2010).

446 Our analysis of 22 spring barley accessions showed that heatwave effects did not appear

447 to be significantly dependent on accession. One can only speculate if an accession

448 specific response would have shown if the applied heatwave had been less extreme, or if

449 other accessions e.g. accessions adapted to warm drought prone environments had been

450 included.

451 The recorded complexity in the response patterns to applied treatments (Fig. 2) will not

452 simplify the task for plant breeders. Various studies have represented $\mathrm{CO}_{2}-$

453 responsivenes as a potential breeding target that has not previously been exploited

454 (Manderscheid and Weigel, 1997; Ziska et al., 2004; Franzaring et al., 2013). In the

455 present study, the heatwave response was independent of the basic treatment, and

456 consequently the higher grain yield from $\mathrm{eCO}_{2}$ continuously lead to the highest grain

457 yield being produced under $\mathrm{eCO}_{2}+\mathrm{H}$ suggesting that $\mathrm{CO}_{2}$-responsivenes is beneficial in

458 a future climate with higher occurrence of heatwaves. Correlating $\mathrm{CO}_{2}$-responsiveness

459 (increased grain yield under $\mathrm{eCO}_{2}$ ) with yield in the eTmp\&eCO $\mathrm{CO}_{2}+\mathrm{H}$ scenario in the 460 present study was though non-significant.

461 The optimal climate resilient cultivar is high yielding in environments with climate 462 stresses over its life cycle. Yet, among accessions in the present study, stability and high 
463 grain yield were rarely characteristics of the same accession. Stability over treatments 464 were combined with low yield in the eTmp\&eCO $\mathrm{CO}_{2}+\mathrm{H}$ treatment, and poor stability 465 combined with high yield in the eTmp\&eCO $\mathrm{CO}_{2}+\mathrm{H}$ treatment. Accessions that were stable 466 and/or high yielding in the eTmp\&e $\mathrm{eCO}_{2}+\mathrm{H}$ treatment are potential candidates in

467 breeding programs aiming at diminishing climate caused losses in production, 468 especially if the desired traits can be easily exploited using marker assisted selection 469 (Ingvordsen et al., 2015b).

\section{5. Conclusion}

472 Translation of findings from studies of environmental effects under artificial conditions

473 to actual field conditions needs to be carefully considered. Environmental factors like

474 light, water, nutrients and temperature conditions are much more variable under field

475 conditions and plants are exposed to a verity of beneficial and pathogenic

476 microorganism and will possible influence the magnitude of the findings. However,

477 manipulating temperature and mimicking heatwaves under field conditions is only

478 partly possible so far (Kimball et al., 2007; Bruhn et al., 2013). Therefore results from

479 studies using controlled growth conditions are sometime the best option to gain

480 knowledge about future climate change related effect on crop production, and relative

481 differences between temperature associated treatments. .

482 Under future climate conditions decreased summer precipitation is projected for 483 southern Scandinavia (IPCC, 2007). In the present study water allocation was identical 484 in all treatments and pots. However, in the treatments of eTmp and under heatwave 485 conditions increased vapor pressure deficit has despite equal relative humidity changed 486 evapotranspiration conditions from those of the ambient treatment. Therefore, reported 
487 effects of the treatments with eTmp can be concerted responses to heat and water

488 availability. From today's climate to a climate with a 10-day heatwave superimposed to

489 IPCC's worst case scenario around year 2100, we measured an immense 52\% decrease

490 in grain yield over all 22 accessions. Modern accessions were highest yielding and

491 effects of the superimposed heatwave did not depend significantly on accession. With a

492 similar relative yield decrease from the superimposed heatwave in the four basic

493 treatments, final grain yield was predominantly determined by the basic treatments.

494 The 52\% decrease in grain yield strongly emphasize that future temperature extremes

495 exert a great threat to crop production systems and stress the need to continuously

496 identify genotypic variation for breeding future climate resilient cultivars. Together with

497 new better cultivars also diversified cropping systems and management should be

498 prioritized to feed the future world population.

\section{Acknowledgements}

501 We would like to thank all the hands that helped during cultivation, harvest, threshing 502 and measuring, Allan Murphy and Esben Højrup for technical assistance in RERAF.

503 We also thank Air Liquide Danmark A/S for generously supply of the $\mathrm{CO}_{2}$ used in this 504 experiment.

507 This work was supported by the Nordic Council of Ministers (NordForsk) through

508 funding of the network 'Sustainable primary production in a changing 
509 climate','COBRA' (Core Organic II) and the FTP project 'Climate Change Effects on

510 Plant Health'.

511

512

513 Appendix A. Supplementary data

514 Supplementary data associated with this article can be found, in the

515 online version, at $x x x x$ 


\section{References}

Ainsworth, E., Long, S.P., 2005. What have we learned from 15 years of free-air $\mathrm{CO}_{2}$ enrichment (FACE)? A meta-analytic review of the responses of photosynthesis, canopy properties and plant production to rising $\mathrm{CO}_{2}$. New Phytologist, 165, 351-71.

Barber, H.M et al., 2017. Temporally and Genetically Discrete Periods of Wheat Sensitivity to High Temperature. Frontiers in Plant Sci, 8, 51.

Barnabas, B. et al., 2008. The effect of drought and heat stress on reproductive processes in cereals. Plant Cell and Environ, 31, 11-38.

Batts, G.R., et al., 1998. Yield and partitioning in crops of contrasting cultivars of winter wheat in response to $\mathrm{CO}_{2}$ and temperature in field studies using temperature gradient tunnels. Journal of agricultural science, $130,17-27$.

Ben-Ari, T., et al., 2016. Identifying indicators for extreme wheat and maize yield losses. Agricultural and Forest Meteorology, 220, 130-140.

Bencze, S., Veisz, O., et al., 2004. Effects of high atmospheric $\mathrm{CO}_{2}$ and heat stress on phytomass, yield and grain quality of winter wheat. Cereal Research Communications, 32, 75-82.

Bokszczanin, K.L., Fragkostefanakis, S., 2013. Perspectives on deciphering mechanisms underlying plant heat stress response and thermotolerance. Frontiers in plant science, 4, 315.

BoM., 2014. Special Climate Statement 47 - an intense heatwave in central and eastern Australia. Available at http:// www.bom.gov.au/climate/current/statements/scs47.pdf.

Bruhn, D., et al., 2013. Improving the performance of infrared reflective night curtains for warming field plots. Agricultural and Forest Meteorology, 173, 53-62.

Cai, C., et al., 2016. Responses of wheat and rice to factorial combinations of ambient and elevated $\mathrm{CO}_{2}$ and temperature in FACE experiments. Global Change Biology, 22, 856-874.

Challinor, A.J., et al., 2014. A meta-analysis of crop yield under climate change and adaptation. Nature Climate Change, 4, 287-291. 
Ciais, P., et al. 2005. Europe-wide reduction in primary productivity caused by the heat and drought in 2003. Nature, 437, 529-33.

Clausen S.K., et al., 2011. Effects of Single and Multifactor Treatments with Elevated Temperature, $\mathrm{CO}_{2}$ and Ozone on Oilseed Rape and Barley. Journal of Agronomy and Crop Science, 197, 442-453.

Collins, M., et al., 2013. Long-term Climate Change: Projections, Commitments and Irreversibility. In: Climate Change 2013: The Physical Science Basis. Contribution of Working Group I to the Fifth Assessment Report of the Intergovernmental Panel on Climate Change [Stocker, T.F., D. Qin, G.-K. Plattner, M. Tignor, S.K. Allen, J. Boschung, A. Nauels, Y. Xia, V. Bex and P.M. Midgley (eds.)]. Cambridge University Press, Cambridge, United Kingdom and New York, NY, USA.

Conroy, J.P., et al., 1994. Influence of Rising Atmospheric $\mathrm{CO}_{2}$ Concentrations and Temperature on Growth, Yield and Grain Quality of Cereal Crops. Australian Journal of Plant Physiology, 21, 741-758.

DMI, 2014. Danish Meteorological Institute. http://www.dmi.dk/en/klima/ (assessed 15.09.2014).

FAOSTAT, 2017. Food and agriculture data. Available at: http://faostat3.fao.org/faostatgateway/go/to/download/C/CC/E (assessed 29.03.2017).

Fischer, E.M., Schär, C., 2009. Future changes in daily summer temperature variability: driving processes and role for temperature extremes. Climate Dynamics, 33, 917-935.

Fischer, E.M., Schär, C., 2010. Consistent geographical patterns of changes in high-impact European heatwaves. Nature Geoscience, 3, 398-403.

Fitzgerald, G.J., et al. 2016. Elevated atmospheric $\left[\mathrm{CO}_{2}\right]$ can dramatically increase wheat yields in semiarid environments and buffer against heat waves. Global Change Biology, 22, 2269-2284.Franzaring, J.A., et al., 2013. Responses of old and modern cereals to $\mathrm{CO}_{2}$-fertilisation. Crop and Pasture Science, 64, 943-956.

Ghaly, A.E., Alkoaik, F.N., 2010. Extraction of Protein from Common Plant Leaves for Use as Human Food. American Journal of Applied Sciences, 7, 331-342.

Gourdji, S.M., et al., 2013. Global crop exposure to critical high temperatures in the reproductive period: historical trends and future projections. Environmental Research Letters, 8, 1-10. 
Hakala, K., et al., 2012. Sensitivity of barley varieties to weather in Finland. The Journal of Agricultural Science, $150,145-160$.

Hay, R.K., 1995. Harvest index : a review of its use in plant breeding and crop physiology. Annual applied biology, 126, 197-216.

Högy, P., et al., 2013. Impacts of temperature increase and change in precipitation pattern on crop yield and yield quality of barley. Food chemistry, 136, 1470-7.

Ingvordsen, C.H., et al. 2015a. Significant decrease in yield under future climate conditions: Stability and production of 138 spring barley accessions. European Journal of Agronomy, 63, 105-113.

Ingvordsen, C.H., et al. 2015b. Genome-wide association study of production and stability traits in barley cultivated under future climate scenarios. Molecular Breeding, 35:85.

IPCC. 2007. Climate Change 2007: The Physical Science Basis. Contribution of Working Group I to the Fourth Assessment Report of the Intergovernmental Panel on Climate Change; Solomon, S., D. Qin, M. Manning, Z. Chen, M. Marquis, K.B. Averyt, M. Tignor and H.L. Miller (eds.);. Cambridge University Press, Cambridge, United Kingdom and New York, NY, USA.

Jablonski, L.M., et al., 2002. Plant reproduction under elevated $\mathrm{CO}_{2}$ conditions: a meta-analysis of reports on 79 crop and wild species. New Phytologist, 156, 9-26.

Kimball, B., et al., 2007. Infrared heater arrays for warming ecosystem field plots. Global Change Biology, 14, 309-320.

Lawlor, D.W., Mitchell, R.A.C., 1991. The effects of increasing $\mathrm{CO}_{2}$ on crop photosynthesis and productivity: a review of field studies. Plant, Cell and Environment, 14, 807-818.

Lesk, C., et al., 2016. Influence of extreme weather disasters on global crop production. Nature, 529, 8487.

Lobell, D.B., et al., 2011. Climate trends and global crop production since 1980. Science, 333, 616-20.

Long, S.P., et al., 2006. Food for thought: lower-than-expected crop yield stimulation with rising $\mathrm{CO}_{2}$ concentrations. Science, 312, 1918-21. 
Manderscheid, R., et al., H-J. 2009. Effects of free air carbon dioxide enrichment and nitrogen supply on growth and yield of winter barley cultivated in a crop rotation. Field Crops Research, 110, 185-196.

Manderscheid, R., Weigel, H.J., 1997. Photosynthetic and growth responses of old and modern spring wheat cultivars to atmospheric $\mathrm{CO}_{2}$ enrichment. Agriculture, Ecosystems \& Environment, 64, 65-73.

Meehl, G., Tebaldi, C., 2004. More intense, more frequent, and longer lasting heat waves in the 21st century. Science, 305, 994-997.

Morison, J.I.L, Lawlor, D.W., 1999. Interactions between increasing $\mathrm{CO}_{2}$ concentration and temperature on plant growth. Plant, Cell and Environment, 22, 659-682.

R core Team., 2015. R: A language and environment for statistical computing. R Foundation for Statistical Computing, Vienna, Austria. URL http://www.R-project.org/.

Ray, D.K., et al., 2015. Climate variation explains a third of global crop yield variability. Nature communications, 6, 5989-5989.

Reyer, C.P.O., 2013. A plant's perspective of extremes: terrestrial plant responses to changing climatic variability. Global change biology, 19, 75-89.

Roemer, T., 1917. Sind die ertragsreichen Sorten ertragssicherer? Mitteilung Deutsche LandwirtschaftsGesellschaft, 32, 87-89.

Sakata, T., et al., 2000. Effects of High Temperature on the Development of Pollen Mother Cells and Microspores in Barley Hordeum vulgare L. Journal of Plant Research, 113, 395-402.

Siebers, M.H., et al., 2017. Simulated heat waves during maize reproductive stages alter reproductive growth but have no lasting effect when applied during vegetative stages. Agriculture, Ecosystems and Environment 240, 162-170.

Stone, P.J., Nicolas, M.E. 1994. Wheat Cultivars Vary Widely in their Responses of Grain Yield and Quality to Short Periods of Post-anthesis Heat Stress. Australian Journal of Plant Physiology, 21, 887900 , 
Stratonovitch, P., Semenov, M.A. 2015. Heat tolerance around flowering in wheat identified as a key trait for increased yield potential in Europe under climate change. Journal of Experimental Botany, 66, 35993609.

Tack, J., Barkley, A., Nalley, L.L, 2015. Effect of warming temperatures on US wheat yields. PNAS 112, 6931-6936.

Tewolde, H., et al., 2006. Wheat Cultivars Adapted to Post-Heading High Temperature Stress. Journal of Agronomy and Crop Science, 192, 111-120.

Trenberth, K.E., Fasullo, J.T., 2012. Climate extremes and climate change: The Russian heat wave and other climate extremes of 2010. Journal of Geophysical Research: Atmospheres, 117, 1-12.

Wricke, G., 1962. Über eine Methode zur Erfassung der okologischen Streubreite in Feldversuchen. Z. Pflanzenzuchtg. 47, 92-96.

Zadoks, J.C., et al., 1974. A decimal code for the growth stages of cereals. Weed Research, 14, 415-421.

Ziska, L.H., et al., 2004. Quantitative and qualitative evaluation of selected wheat varieties released since 1903 to increasing atmospheric carbon dioxide: can yield sensitivity to carbon dioxide be a factor in wheat performance? Global Change Biology 10, 1810-1819.

Ziska, L.H., et al., 1997. Growth and Yield Response of Field-Grown Tropical Rice to Increasing Carbon Dioxide and Air Temperature. Agronomy Journal 89, 45-53. 
Table 1. The tested barley accessions with mean yield and stability across all treatments; ambient, elevated temperature, elevated $\mathrm{CO}_{2}$, elevated temperature and elevated $\mathrm{CO}_{2}$ in combination and all four treatments +/-heatwave. Modern cultivar (mCV), old cultivar (oCV), landrace (LR), genebank number (NGB), environmental variance $\left(S^{2}\right)$ and Wricke's ecovalence $\left(W^{2}\right)$. The accessions are sorted after the mean grain yield across the eight treatments $\left(m_{i}\right)$, and numbers in brackets are the ranking based on their stability indices. *Values for Drost P. based on seven of the eight treatments (eTemp $+\mathrm{H}$ excluded due to faulty watering).

\begin{tabular}{llcclcccc}
$\begin{array}{l}\text { Accessions } \\
\text { name }\end{array}$ & NGB / Breeder & $\begin{array}{c}\text { Culton } \\
\text { type }\end{array}$ & $\begin{array}{c}\text { Sub } \\
\text { type }\end{array}$ & $\begin{array}{l}\text { Country of } \\
\text { origin / Country } \\
\text { of breeding }\end{array}$ & $\begin{array}{c}\text { Year of } \\
\text { release }\end{array}$ & $\boldsymbol{m}_{\boldsymbol{i}}$ & $\boldsymbol{S}^{\mathbf{2}}$ & $\boldsymbol{W}^{\mathbf{2}}$ \\
\hline Bjørne & NGB9326 & LR & 6 & unknown & & 6.25 & $6.19(18)$ & $5.23(6)$ \\
Evergreen & Nordic Seed A/S Plant Breeding & mCV & 2 & Denmark & 2010 & 6.19 & $9.35(22)$ & $17.46(21)$ \\
Brio & NGB9327 & oCV & 6 & Sweden & 1924 & 6.13 & $6.04(16)$ & $5.93(9)$ \\
Brage & Graminor Plant Breeding & mCV & 6 & Norway & 2010 & 5.97 & $5.15(8)$ & $5.89(8)$ \\
Anakin & Sejet Plant Breeding I/S & mCV & 2 & Denmark & 2006 & 5.91 & $5.83(12)$ & $5.09(5)$ \\
Solenbyg & NGB13402 & LR & 6 & Norway & & 5.90 & $7.38(19)$ & $8.41(14)$ \\
Prestige & NGB16750 & mCV & 2 & France & 2000 & 5.88 & $2.68(2)$ & $9.00(15)$ \\
Kushteki & NGB6288 & LR & 6 & Afghanistan & & 5.87 & $5.48(10)$ & $2.37(1)$ \\
Moscou & NGB9482 & LR & 2 & unknown & & 5.83 & $5.93(14)$ & $4.00(3)$ \\
Drost P.* & NGB6281 & oCV & 2 & Denmark & 1951 & 5.81 & $4.90(7)$ & $7.30(13)$ \\
Alliot & NGB16757 & mCV & 2 & Denmark & 1999 & 5.73 & $4.42(6)$ & $15.03(19)$ \\
Sebastian & Sejet Plant Breeding I/S & mCV & 2 & Denmark & 2002 & 5.72 & $3.89(4)$ & $5.98(10)$ \\
Griechische & NGB9333 & LR & 6 & Greece & & 5.56 & $5.57(11)$ & $4.11(4)$ \\
Arve & NGB11311 & mCV & 6 & Norway & 1990 & 5.36 & $5.90(13)$ & $3.72(2)$ \\
Grenoble I & NGB9378 & LR & 6 & France & & 4.63 & $8.67(21)$ & $23.32(22)$ \\
Edvin & Boreal Plant Breeding & mCV & 6 & Finland & 2008 & 4.54 & $7.95(20)$ & $11.76(17)$ \\
Vilm & NGB9435 & LR & 2 & Germany & & 4.21 & $5.98(15)$ & $5.34(7)$ \\
Anita & NGB15250 & oCV & 6 & Norway & 1962 & 4.20 & $6.15(17)$ & $7.27(12)$ \\
Mari & NGB1491 & oCV & 2 & Sweden & 1960 & 4.12 & $5.36(9)$
\end{tabular}




\begin{tabular}{llllllllr} 
Oslo & NGB9315 & LR & 6 & Norway & & 4.09 & $1.80(1)$ & $10.25(16)$ \\
Königsberg & NGB9310 & LR & 6 & unknown & & 3.65 & $3.12(3)$ & $16.71(20)$ \\
Alf & NGB4707 & mCV & 2 & Denmark & 1978 & 3.41 & $4.20(5)$ & $6.32(11)$ \\
\hline
\end{tabular}

Table 2. Model estimates for grain yield, aboveground vegetative biomass and harvest index (HI) for the 22 barley accessions with $95 \%$

standard confidence intervals, when cultivated under ambient (amb), elevated levels of temperature (eTmp) and $\mathrm{CO}_{2}\left(\mathrm{eCO}_{2}\right)$ as single factors or in combination $(\mathrm{eTmp \& eCO})$ and with $(+\mathrm{H})$ and without a 10-day heatwave around anthesis. The $p$-values indicate the difference to the production parameter under ambient conditions (amb). ${ }^{* * *} p<0.001 ; * *<0.01 ; * p<0.05$. Difference in $\%$ is relative to ambient conditions (amb).

\begin{tabular}{|c|c|c|c|c|c|c|}
\hline Treatment & $\begin{array}{l}\text { Grain yield } \\
\left(\text { g plant }^{-1}\right)\end{array}$ & $\begin{array}{c}\text { Difference in } \\
\% \\
\end{array}$ & $\begin{array}{l}\text { Aboveground vegetative } \\
\text { biomass }\left(\mathrm{g} \mathrm{plant}^{-1}\right)\end{array}$ & $\begin{array}{l}\text { Difference } \\
\text { in \% }\end{array}$ & HI (\%) & $\begin{array}{l}\text { Difference } \\
\text { in \% }\end{array}$ \\
\hline $\mathrm{amb}$ & $7.16 \pm 0.51$ & - & $8.33 \pm 0.86$ & - & $45.31 \pm 2.51$ & - \\
\hline eTmp & $4.06 \pm 0.51^{* * *}$ & $-43.3( \pm 5.6)$ & $7.94 \pm 0.86$ & $-4.6( \pm 7.7)$ & $35.76 \pm 2.53^{* * *}$ & $-21.1( \pm 4.9)$ \\
\hline $\mathrm{eCO}_{2}$ & $9.00 \pm 0.51^{* * *}$ & $25.8( \pm 7.3)$ & $11.21 \pm 0.86^{* * *}$ & $34.7( \pm 9 ., 9)$ & $45.31 \pm 2.51$ & 0 \\
\hline eTmp\&eCO 2 & $5.90 \pm 0.51^{* * *}$ & $-17.5( \pm 8.1)$ & $9.99 \pm 0.86^{* * *}$ & $20.1( \pm 10.2)$ & $35.75 \pm 2.51^{* * *}$ & $-21.1( \pm 4.9)$ \\
\hline $\mathrm{amb}+\mathrm{H}$ & $4.51 \pm 0.51^{* * *}$ & $-37.0( \pm 6.7)$ & $10.27 \pm 0.86^{* * *}$ & $23.4( \pm 9.1)$ & $27.50 \pm 2.53^{* * *}$ & $-39.3( \pm 4.7)$ \\
\hline $\mathrm{eTmp}+\mathrm{H}$ & $2.70 \pm 0.53^{* * *}$ & $-62.3( \pm 6.6)$ & $8.11 \pm 0.86$ & $-2.6( \pm 9.0)$ & $23.66 \pm 2.53^{* * *}$ & $-47.8( \pm 4.7)$ \\
\hline $\mathrm{eCO}_{2}+\mathrm{H}$ & $5.23 \pm 0.51^{* * * *}$ & $-26.9( \pm 6.9)$ & $14.33 \pm 0.86^{* * *}$ & $72.3( \pm 14.1)$ & $27.50 \pm 2.53^{* * *}$ & $-39.3( \pm 4.7)$ \\
\hline eTmp\&eCO ${ }_{2}+\mathrm{H}$ & $3.42 \pm 0.51^{* * *}$ & $-52.2( \pm 6.5)$ & $11.34 \pm 0.86^{* * *}$ & $36.3( \pm 9.9)$ & $23.66 \pm 2.53^{* * *}$ & $-47.8( \pm 4.7)$ \\
\hline
\end{tabular}




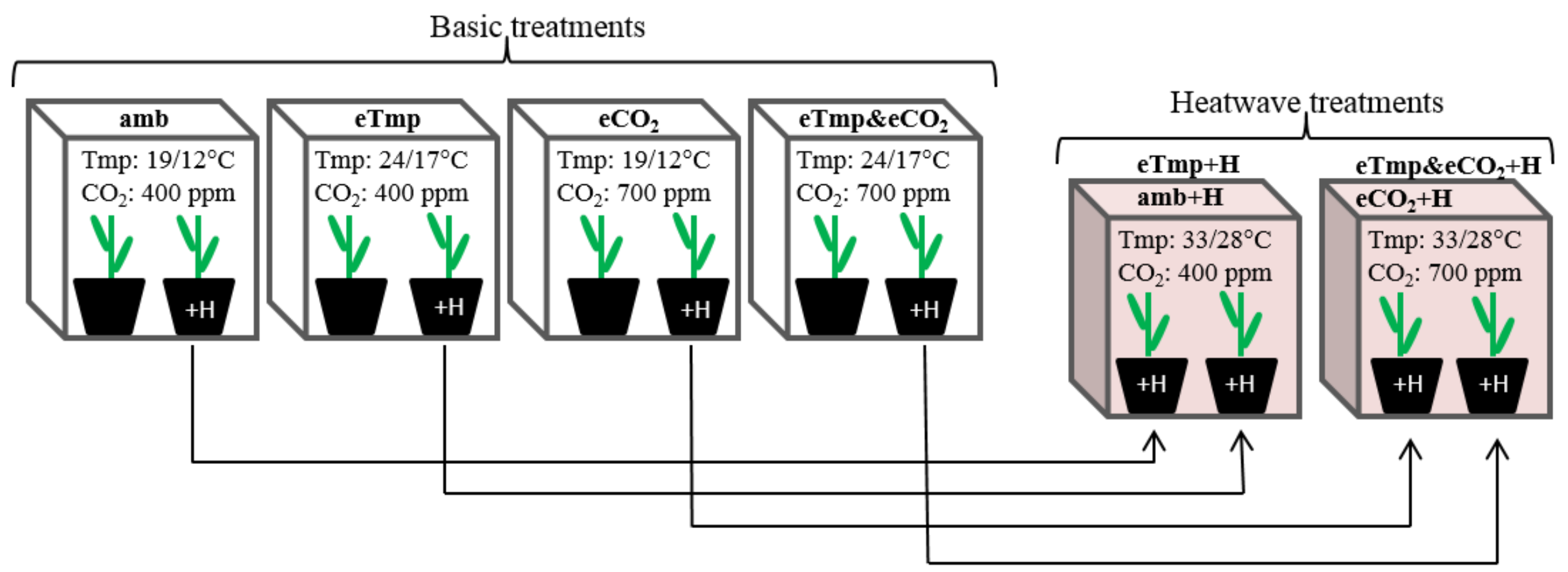

Fig. 1. Schematic overview of the four climatic scenarios and the superimposed 10-day heatwave treatment, illustrated for one accession. For the basic treatments it was one treatment per chamber and during heatwave treatments, two basic treatments in each of the heatwave chambers. amb: ambient conditions, $\mathrm{eCO}_{2}$ : elevated $\mathrm{CO}_{2}$, eTmp: elevated temperature, eTmp\&eCO $\mathrm{CO}_{2}$ : elevated temperature and elevated $\mathrm{CO}_{2}$ in combination, $+\mathrm{H}$ : heatwave superimposed to basic treatment. For each accession one pot in the basic treatment was transferred to the heatwave treatment as indicated with arrows. 


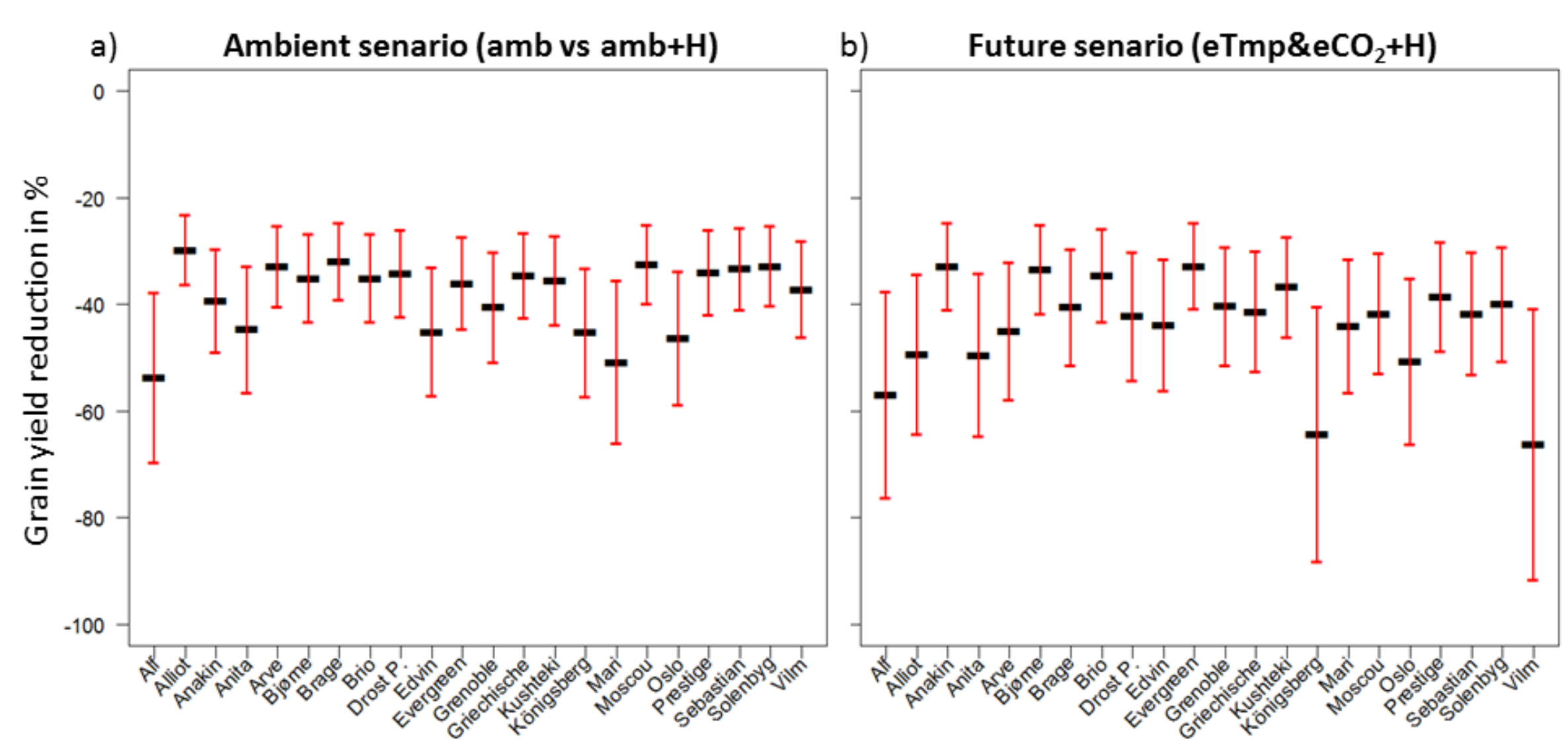

Fig. 2. Reduction in grain yield of 22 barley accessions after a 10-day heatwave superimposed around flowering to plants grown under climatic conditions corresponding to (a) ambient conditions (amb) or (b) futur senario with elevated temperature and $\mathrm{CO}_{2}\left(\mathrm{eTmp}_{\mathrm{TeCO}}\right)$. 


\section{Supplemental}

Table A.1. Set point and experimental levels of temperature, atmospheric concentration of $\mathrm{CO}_{2}\left(\left[\mathrm{CO}_{2}\right]\right)$ and humidity \pm standard deviations in the six chambers; four chambers mimicking basic treatments and two chambers mimicking basic treatments with a superimposed heatwave $(+\mathrm{H})$.

\begin{tabular}{|c|c|c|c|c|c|c|}
\hline & \multicolumn{2}{|c|}{ Temperature (day/night) } & \multicolumn{2}{|c|}{$\left[\mathrm{CO}_{2}\right]$ (constant) } & \multicolumn{2}{|c|}{ Humidity (day/night) } \\
\hline & $\underline{\text { Set point }}$ & $\underline{\text { Experimental }}$ & $\underline{\text { Set point }}$ & $\underline{\text { Experimental }}$ & $\underline{\text { Set point }}$ & $\underline{\text { Experimental }}$ \\
\hline Ambient & $19 / 12^{\circ} \mathrm{C}$ & $18.36 \pm 2.18 / 13.02 \pm 2.48$ & 400 ppm & $451.54 \pm 40.65$ & $55 / 70$ & $56.55 \pm 4.53 / 67.43 \pm 5.41$ \\
\hline eTmp & $24 / 17^{\circ} \mathrm{C}$ & $22.97 \pm 2.18 / 18.20 \pm 2.45$ & 400 ppm & $459.72 \pm 40.85$ & $55 / 70$ & $56.64 \pm 4.61 / 67.25 \pm 5.43$ \\
\hline $\mathrm{eCO}_{2}$ & $19 / 12^{\circ} \mathrm{C}$ & $18.22 \pm 2.23 / 13.04 \pm 2.45$ & 700 ppm & $700.27 \pm 23.18$ & $55 / 70$ & $56.63 \pm 4.65 / 67.51 \pm 5.38$ \\
\hline eTmp \& $\mathrm{eCO}_{2}$ & $24 / 17^{\circ} \mathrm{C}$ & $23.05 \pm 2.24 / 18.08 \pm 2.44$ & 700 ppm & $693.89 \pm 23.76$ & $55 / 70$ & $56.66 \pm 4.69 / 67.32 \pm 5.42$ \\
\hline$+\mathrm{H}$ & $33 / 28^{\circ} \mathrm{C}$ & $32.41 \pm 2.63 / 28.01 \pm 2.52$ & 400 ppm & $446.88 \pm 19.09$ & $55 / 70$ & $56.47 \pm 4.41 / 67.59 \pm 5.24$ \\
\hline$+\mathrm{H} \& \mathrm{eCO}_{2}$ & $33 / 28^{\circ} \mathrm{C}$ & $32.42 \pm 2.52 / 28.02 \pm 2.50$ & $700 \mathrm{ppm}$ & $703.14 \pm 21.00$ & $55 / 70$ & $56.43 \pm 4.55 / 67.55 \pm 5.20$ \\
\hline
\end{tabular}




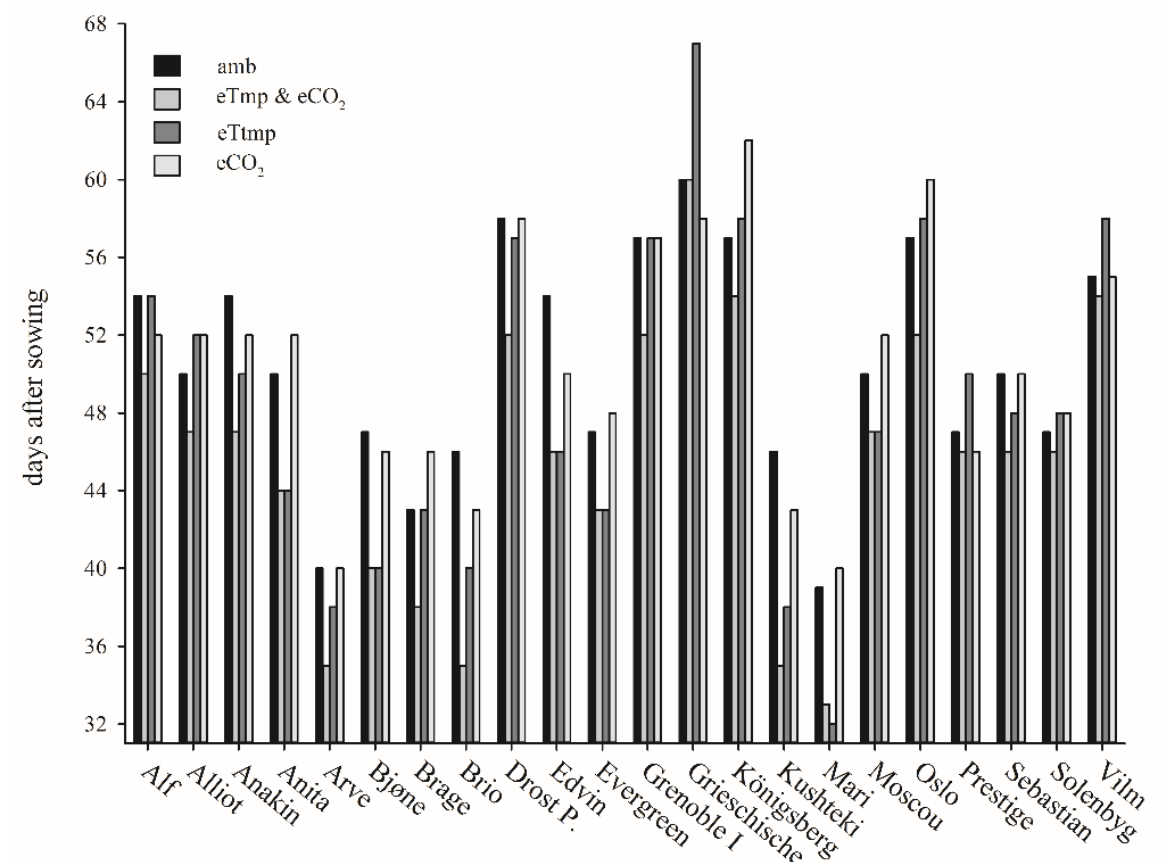

Fig. A.1. Number of growing days before transfer to the heatwave treatment. An accession was transferred when four of eight plants reached Zadoks growth stage 49. Ambient conditions: amb, elevated $\mathrm{CO}_{2}: \mathrm{eCO}_{2}$, elevated temperature: eTmp and elevated $\mathrm{CO}_{2}$ and temperature in combination: eTmp \& eCO 

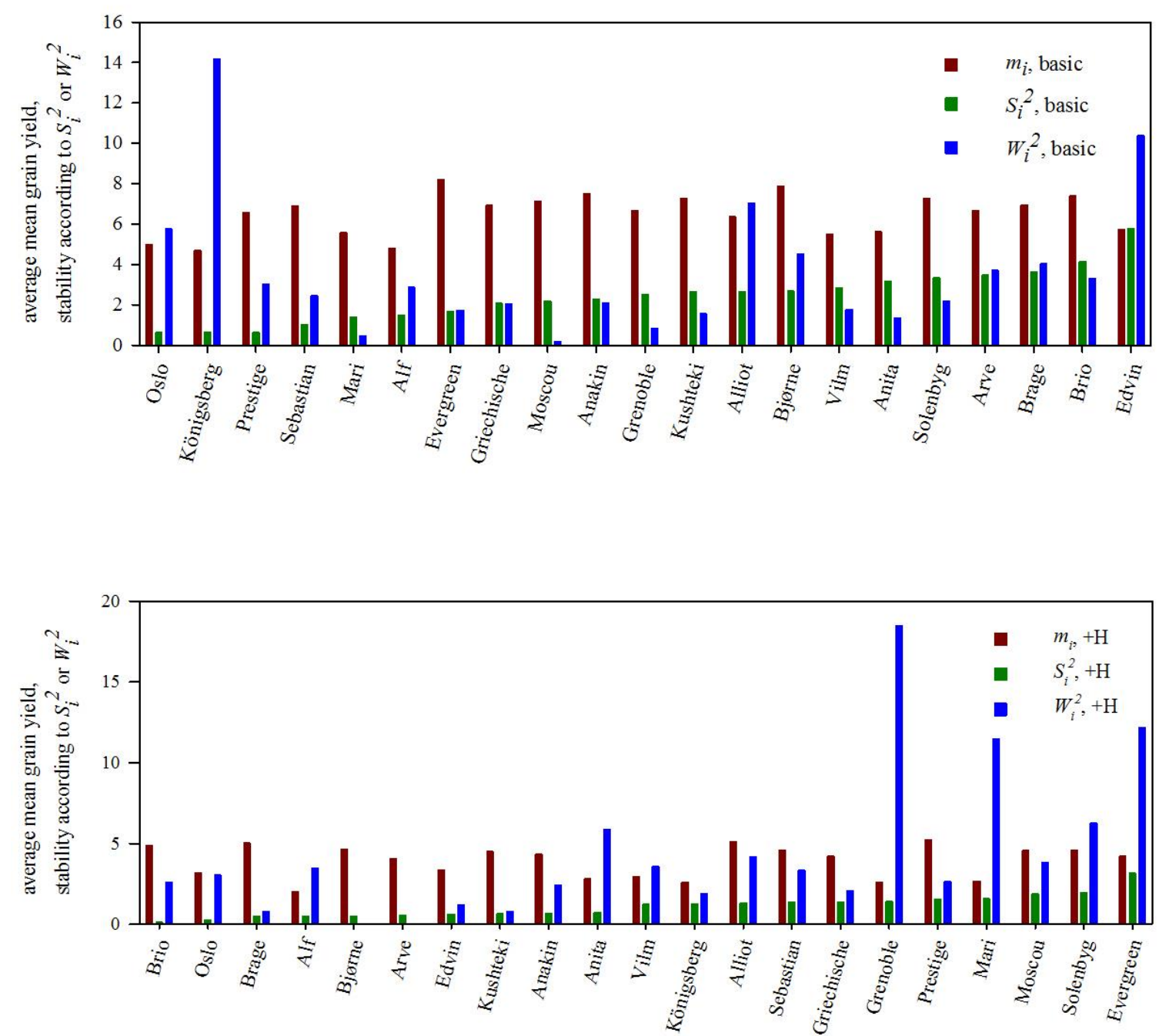

Fig. A.2. Environmental variance $\left(S_{i}^{2}\right)$, Wricke's ecovalence $\left(W_{i}^{2}\right)$ and mean grain yield across either the four basic treatments (top) or four basic+Heatwave $(+\mathrm{H})$ treatments (bottom). Pearson's correlation of $S_{i}^{2}$ between the basic and basic $+\mathrm{H}$ treatments was -0.335 with p-value at 0.135 . Drost P. not included, as watering in the eTemp+H treatment was defective. 


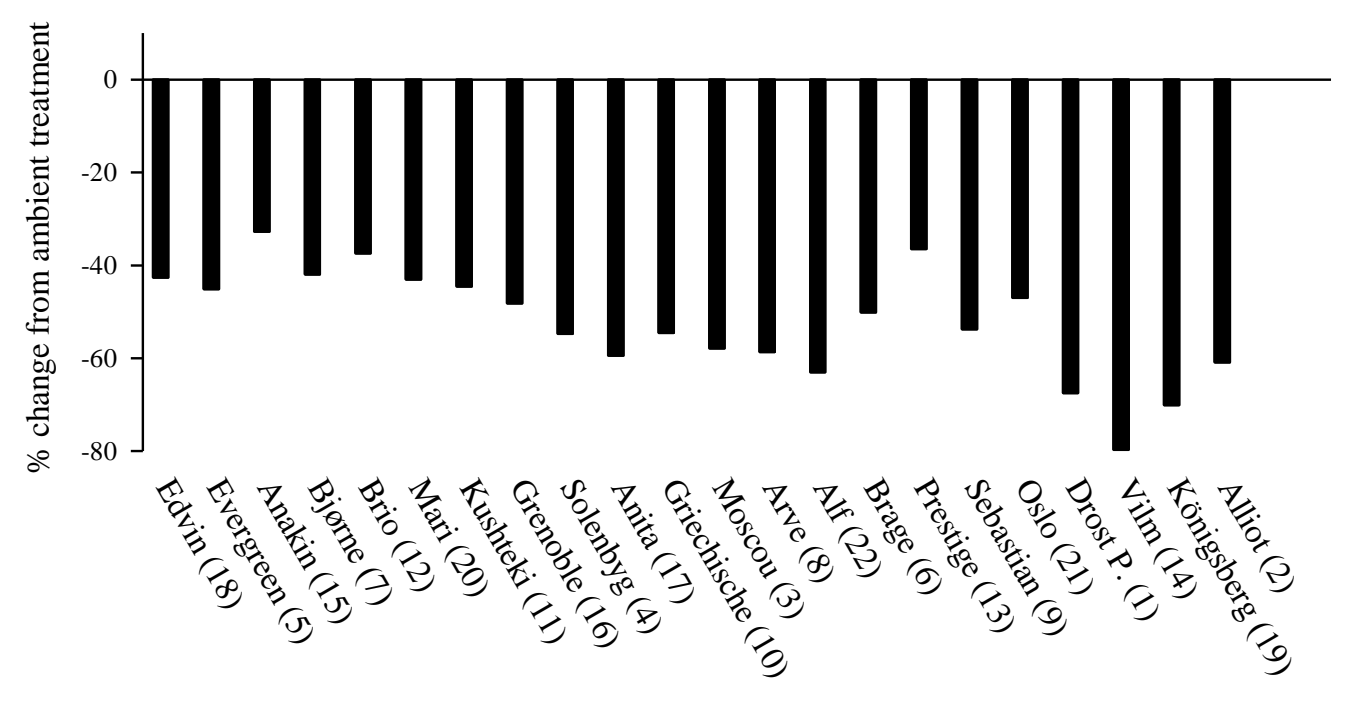

Fig. A.3. Change (\%) in grain yield of the 22 spring barley accessions exposed to ambient climate treatment of $19 / 12^{\circ} \mathrm{C}($ day/night $)$ and $400 \mathrm{ppm} \mathrm{CO}_{2}$ and no heatwave exposure and the future climate scenario with elevated temperature $\left(24 / 17^{\circ} \mathrm{C}\right)$ and elevated $\mathrm{CO}_{2}(700 \mathrm{ppm})$ in combination and a superimposed 10 day heatwave around flowering. In brackets is the rank (1: highest, 22: lowest) according to grain yield under basic ambient conditions. 


\section{Model description}

The model used for generating estimates for Table 2 is of the form

$$
Y_{i}=\alpha+\beta_{T}+\beta_{C O 2}+\beta_{H}+\beta_{T: C O 2}+\beta_{T: H}+\beta_{C O 2: H}+Z_{A C C \mid P O T}+\varepsilon_{i}
$$

Where the response $\mathrm{Y}$ is one of Grain Yield, Biomass or Harvest Index. The treatment types elevated Temperature $(\mathrm{T})$ and elevated $\mathrm{CO}_{2}\left(\mathrm{CO}_{2}\right)$ together with the superimposed Heatwave $(\mathrm{H})$ enters into the parameters according to the treatment of the $i$ 'th observation and presence of heatwave or not. $Z$ denotes randomized effects of Accessions and Pots, nested within Accessions. Absence of treatment refers to the ambient conditions. Thus, if observation $i$ has been subject to elevated Temperature but no Heatwave and no elevated $\mathrm{CO}_{2}$, the model for observation $i$ is

$$
Y_{i}=\alpha+\beta_{T}+Z_{A C C \mid P O T}+\varepsilon_{i},
$$

While an observation $i$ that has been subject to both elevated Temperature and a superimposed Heatwave, but not elevated $\mathrm{CO}_{2}$, has the model

$$
Y_{i}=\alpha+\beta_{T}+\beta_{H}+\beta_{T: H}+Z_{A C C \mid P O T}+\varepsilon_{i}
$$

The estimated difference between these two scenarios is thus described by the parameter sum $\beta_{H}+\beta_{T: H}$.

Parameters estimates in the basic model (1) is listed in Table A.2. below for all three response types.

\begin{tabular}{|c|c|c|c|c|c|c|c|c|c|}
\hline & \multicolumn{3}{|c|}{ GrY } & \multicolumn{3}{|c|}{ BiM } & \multicolumn{3}{|c|}{ HI } \\
\hline & estimate & $\mathrm{sd}$ & $\mathrm{p}$ & estimate & $\mathrm{Sd}$ & $\mathrm{p}$ & estimate & $\mathrm{sd}$ & $\mathrm{p}$ \\
\hline$\alpha$ & 7.16 & 0.26 & $<0.0001 * * *$ & 8.33 & 0.44 & $<0.0001 * * *$ & 45.31 & 1.28 & $<0.0001 * * *$ \\
\hline$\beta_{\mathrm{CO} 2}$ & 1.84 & 0.23 & $<0.0001 * * *$ & 2.88 & 0.33 & $<0.0001 * * *$ & - & - & NS \\
\hline $\boldsymbol{\beta}_{T}$ & -3.10 & 0.23 & $<0.0001 * * *$ & -0.39 & 0.33 & 0.25 & -9.56 & 1.23 & $<0.0001 * * *$ \\
\hline $\boldsymbol{\beta}_{H}$ & -2.65 & 0.28 & $<0.0001 * * *$ & 1.93 & 0.33 & $<0.0001 * * *$ & -17.81 & 1.24 & $<0.0001 * * *$ \\
\hline$\beta_{C O 2: T}$ & - & - & NS & -0.83 & 0.38 & $0.03 *$ & - & - & NS \\
\hline$\beta_{C O 2: H}$ & -1.12 & 0.32 & $0.0006 * * *$ & 1.18 & 0.38 & $0.002 * *$ & - & - & NS \\
\hline $\boldsymbol{\beta}_{T: H}$ & 1.29 & 0.32 & $0.0001 * * *$ & -1.77 & 0.38 & $<0.0001 * * *$ & 5.72 & 1.75 & $0.001 * *$ \\
\hline
\end{tabular}

Table A.2. Parameter estimates in the random effects model (1), for responses Grain Yield (GrY), Biomass (BiM) and Harvest Index (HI) and SD for estimates. 
